\title{
Five Lenses for Designing Exertion Experiences
}

\author{
Florian 'Floyd' Mueller, Damon Young \\ Exertion Games Lab \\ RMIT University \\ Melbourne, Australia \\ \{floyd, damon\}@exertiongameslab.org
}

\begin{abstract}
The field of HCI has increasingly looked at ways to support the physically active human being, however, new work suggests that the field has only begun to understand the many virtues of exertion. To further the field, we present a set of five design lenses extended primarily from sports philosophy literature to help approach exertion not just as a means of deferring death, but also as an opportunity for personal growth. The lenses facilitate learning how to appreciate a void (Reverie), welcome pleasure (Pleasure), become humble (Humility), as well as be fearful and excited simultaneously (Sublime), whilst being more carefully aware of one's own body (Oneness). Using these lenses, we articulate associated technology opportunities through related work as well as our own craft knowledge. With our work, we aim to support designers who want to facilitate the many virtues of exertion so that ultimately more people profit from the many benefits of being physically active.
\end{abstract}

\section{Author Keywords}

Exertion interface; whole-body interaction; exergame; exertion games; sport; movement-based interaction

ACM Classification Keywords: H.5.2. [Information Interfaces and Presentation]: User Interfaces Miscellaneous.

\section{General terms: Design, Human Factors}

\section{INTRODUCTION}

The coming together of exertion and interactive technology is of increasing interest in HCI (e.g. [31, 45, 50, 52, 57, 72, $82,84,90])$, fuelled by technological advancements such as game console accessories that support exertion activities (for example Microsoft Xbox's Kinect), wearable technologies that sense bodily movement (for example activity trackers and smart watches) and sports apparel that

Permission to make digital or hard copies of all or part of this work for personal or classroom use is granted without fee provided that copies are not made or distributed for profit or commercial advantage and that copies bear this notice and the full citation on the first page. Copyrights for components of this work owned by others than the author(s) must be honored. Abstracting with credit is permitted. To copy otherwise, or republish, to post on servers or to redistribute to lists, requires prior specific permission and/or a fee. Request permissions from

Permissions@acm.org.

CHI 2017, May 06 - 11, 2017, Denver, CO, USA Copyright is held by the owner/author(s). Publication rights licensed to ACM. ACM 978-1-4503-

4655-9/17/05...\$15.00 DOI: http://dx.doi.org/10.1145/3025453.3025746 measure bodily responses (for example heart rate monitors and smart socks [1]). Despite these technical developments, recent work suggests that the field has only begun to understand the many virtues of exertion [29, 50, 80]. Furthermore, commentaries have emerged that lament the fact that a rather narrow view is taken on what it means to be physically active, possibly due to an overly simplistic health agenda where the underlying assumption is that people engage in exertion activities for health reasons alone $[28,50,52,74]$. This view assumes that the sole point of exertion is to "fix" immediate health issues, or, in other words, to defer death. Much of this debate about exercise and health often portrays the image of the body as a simple machine, which requires a "tune up". In this dualist picture, the body is a "thing", which is somehow possessed by a thinking mind. The problem with this Cartesian outlook is it obscures the enormous interplay between mental and physical activities; the ways in which exertion enriches and enhances the mind, and the way the mind guides, informs and reflects upon physical exertion.

To aid exertion designers in going beyond this dualist view, we introduce HCI to sports philosophy literature that has long suggested that exertion can much more than only deferring death; rather that it can be an integral part of personal growth, helping people identify who they are, who they want to be and how to get there $[39,91]$. Thanks to the opportunity of using interactive technology to "design sports" [57], we believe HCI now has a unique chance to create exertion systems that allow the facilitation of personal growth, and we see this paper as a starting point towards making this a reality. However, when it comes to an understanding about how to design interactive technology for exertion experiences from a perspective of personal growth, there appears to be only limited knowledge available. To address this, we make a conceptual contribution in the form of a theoretical discussion around a set of five lenses to help designers see exertion through additional perspectives.

We are inspired by Klemmer et al.'s "How bodies matter" [38] and Dourish's "Embodied interaction" [19] who, like us, identified a trend towards more body-centric design and in response proposed a set of lenses to guide future research. In regards to the choice of lenses, we were inspired by the concept of virtues that has previously been used in ethical philosophy in general [49] and sports 
philosophy in particular $[54,91]$. In particular, we extend the prior philosophical work by Young [91] - who previously suggested our virtues as perspectives on "how to think about exercise" - through a focus on how interactive technology can foster and support the development of these virtues. Virtues treat human behavior as a complex of emotional, perceptual and rational activities, adjusting thoughtfully to changing concepts. A virtue is a desirable disposition: a tendency to do the right thing in the right time and place [91]. But this tendency cannot be reduced to a simple guideline - it can only be developed by acting well in varied real world circumstances. The word "virtue" is simply a Latinized translation of the Greek arete, meaning "excellence". We believe exertion activities can help to develop excellent dispositions and that HCI can aid this process.

The five lenses highlight that exertion can help us grow by facilitating learning how to appreciate a void (Reverie), welcome pleasure (Pleasure), become humble (Humility), as well as be fearful and excited simultaneously (Sublime), whilst being more carefully aware of one's own body (Oneness). These five lenses have one common feature: they ask us to think differently about exertion and associated benefits, departing from the prevalent approach that sees exertion as a mechanical activity for improving physiological functioning. Instead, and while fully recognizing its health benefits, they focus on the experiential aspects of exertion. More specifically, they fall into two unorthodox categories:

(1) Lenses that highlight an unusual state of mind: Reverie, Sublime \& Oneness all shift away from a standard notion of rational, transparently-conscious individuals. They reveal more broad and blurred states of mind, which can be intellectually and emotionally enriching, and which cannot be accessed outside particular forms of exertion.

(2) Lenses that highlight unusual values: Pleasure \& Humility move away from a traditional idea of exercise as a dutiful suffering on the one hand, or vain egotism on the other. Exercise can have surprising joys, including those of pain. Yet it can also undermine vulgar egocentrism, by making our flaws explicit.

We note that these are not all the same kinds of categories, e.g. Humility is a virtue, while Pleasure is one aspect of every virtue. However, given the ubiquity and variety of pleasures in exercise, we thought it necessary to give this notion its own lens. Obviously it appears in other lenses (e.g. Sublime), and suggests other lenses we left out due to space (e.g. Hume's Pride).

We present an initial set of lenses based on our engagement with the literature (where we deliberately ventured outside the usual HCI-related domains such as persuasive health [26] by engaging with sports philosophy) and our own craft knowledge of having designed exertion experiences for over a decade $[5,35,36,57,60,61,63,64,65,66,67,68$, $69,70,73,74]$. We focus on these lenses as we believe they have been underexplored (unlike, for example, "flow" [13]) while they also offer actionable opportunities for designers, complementing design perspectives previously already examined (such as the socially situated nature of exertion experiences [52]). Our discussion includes opportunities for technology design when examining exertion experiences through these lenses to drive the field forward in novel and interesting ways. The value of our work therefore lies in the lenses and their technology considerations; with the design suggestions serving to illustrate that both the lenses and considerations can directly be applied to practical design tasks. They therefore illustrate our point, but are naturally limited by our own design practice and preferences. The technology considerations also highlight that designing for exertion is a complex problem that does not lend itself necessarily to immediate easy solutions. As such, we do not claim that this is a complete set of lenses, but rather, we imagine that in the future additional lenses might emerge that complement our set.

We wrote this paper to support practitioners interested in designing exertion systems as well as for researchers who aim to understand exertion systems and seek a scaffold to structure their analysis. We believe our lenses could also be used to evaluate existing exertion experiences. We think that by continuing to take a limited view on exertion, the field will be unnecessarily constrained, not reaching its full potential and in consequence, people will not be able to benefit fully from the many benefits associated with exertion. They will be bored, uninspired, intimidated, or simply alienated from what they perceive as an "unintelligent" physical culture.

The rest of the paper is organized as follows. We first review related work, then present the lenses along with design opportunities interactive technology can offer. We illustrate our thinking with examples from our own and other people's work.

\section{RELATED WORK}

Prior work has shown that investing physical exertion as part of our interactions with computers results in significantly different experiences compared to the common interactions that involve mouse and keyboard [55]. As a result, several frameworks have emerged that provide a theoretical account of what it means when exertion and interactive technology come together (for examples see [10, $32,37,46,57,79,86])$. These prior works offer different lenses through which one can examine exertion experiences. For example, Consolvo et al. proposed to see exertion through a lens of behavior change facilitation [10]. Similarly, Toscos et al. suggested examining exertion through a lens of goal setting [85]. Mueller et al. suggested looking through lenses of the "responding, moving, sensing and relating" body when augmenting exertion interactions [57]. Segura et al. proposed to examine exertion from a lens of engaging in pleasant movements [79]. Loke and Roberston [46] suggested inspecting exertion experiences 
through a lens of traditional dance, while Yim et al. [90] proposed to examine them through a lens of motivation. Finally, Isbister et al. [32] and Mueller at el. [62] suggested looking at exertion experiences through a lens of design patterns in order to aid the design of better games. These design patterns take the form of guidelines that conceptually sit on a lower practical design level thanks to their "dos" and "don'ts" when compared to the lenses in this paper, however, they informed our work, in particular the technology considerations. For example, our technology consideration of bodily record under the Oneness lens presents one way to understand the guideline "Support selfexpression", while "the world stimulates by threatening" under the Sublime lens explains why designers should "exploit risk".

Despite the advances these frameworks provided, some scholars have lamented that we need even more perspectives to allow for a comprehensive understanding of the phenomenon. For example, Purpura et al. critiqued the state of the field by highlighting the limitations of the current state of the art exertion support systems such as fitness trackers [75]. The authors articulate a dystopian future in which technology provides ongoing feedback on how many calories a person is burning at any point in time. This design fiction aims to emphasize that current technology developments see exertion only through the lens in which people engage in physical activity for immediate health benefits only. The fear of such a future is shared by Linehan et al. who critiqued the field by proposing "Games against Health" [43]. The authors highlight that players might not want to be told by systems such as games to look after their health. The authors therefore propose to examine the design of systems through alternative lenses, such as giving people more autonomy when, how and why they are engaging in exertion activities.

When it comes to exertion in HCI, Marshall et al. [52] have lamented the current prevalent research focus of aiming to address the obesity epidemic that leads to solutions that only have a single aim: maximizing energy expenditure. The authors propose that this ignores all the other lenses through which exertion could be examined [52]. More specifically, Tholander et al. [84] critiqued the currently prevalent instrumental lens that stresses athletic performance, calling for a more experienced-focused lens. Similarly, Hook et al. [29] also lamented on the state of the field, arguing that most exertion-centric design work "has taken a quite instrumental view" that ignores the "pulsating, live, felt body". Consequently, the authors call for a set of lenses that allow seeing the body from this perspective also. Our work aims to be a direct answer to these last two calls, with all our lenses being concerned with experiential rather than instrumental aspects of exertion.

In summary, prior research highlighted that when it comes to interactive technology and exertion, the field does not fully consider the multiple perspectives of exertion experiences, limiting the growth of the field. We address this gap by presenting a set of lenses through which designers can examine exertion experiences. These lenses aim to complement existing perspectives by offering a more detailed picture of the exertion phenomenon, and what this means for exertion designers.

\section{FIVE LENSES}

We begin with a description of each lens that we supplement with a practical example from the sports domain. We unpack each lens into its key facets in order to offer a set of practical handles designers can grapple with as part of their design practice. We then present technology design considerations we identified based on our craft knowledge acquired through the design of exertion experiences for over a decade. The lenses have been derived through a constant back-and-forth between conceptual thinking and practical design work and as such have been developed not through a pre-determined approach but rather through an iterative and integrated process, a process that has been previously successfully used to expand the exertion field [52].

We subscribe to the idea that designing for exertion is best practiced by engaging with exertion [50], as exertion activities are best understood by going through them oneself as it allows for the fullest account of the experience (as suggested by [75]). We admire the prior work that has engaged technology students in sports activities such as rock-climbing in order to support them becoming better exertion designers [23] and we encourage the reader to engage in exertion activities in order to fully transcend our discussion. In order to facilitate this embodied approach, we describe at the end of each lens a practical example exertion activity. This exertion activity might also be useful for teachers, as they can do these activities with their students as a physical way to engage with the lenses.

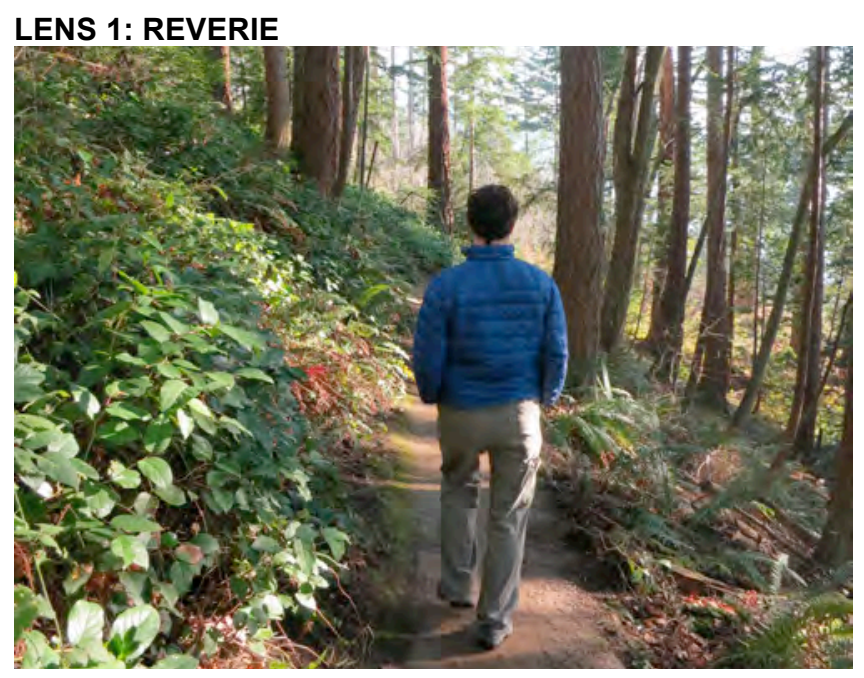

Fig. 1. A refreshing walk in the woods

"I have walked myself into my best thoughts, and I know of no thought so burdensome that one cannot walk away from it."

Soren Kierkegaard 
With the reverie lens, we highlight that people's minds benefit from being stimulated by (light) exertion activity, for example research has shown that exertion activities can positively affect cognitive function [12] such as encouraging innovation and problem solving, which has also made its way into the HCI literature [78]. A typical example activity is walking, as it does not require too much intellectual investment while providing just the right amount of stimulation through the exertion itself as well as by any new environment the walker passes by. Engaging in light exertion activity allows the intellect to relax a little, which has been described through the transient hypofrontality theory [18, 40]: It suggests that during exercise the prefrontal cortex, which is tasked to make general concepts and rules, is turned down while the motor and sensory parts of the brain are turned up during exertion activities [19], which allows for the reorganizing of concepts and previously parted ideas to freely mingle and emerge again. This affords a chance to undo the usual intellectual rigidity, shaking up intellectual routines and seeking novelty. Such benefits have been previously recognized within HCI by Mark Weiser who asked why computing cannot be equally "refreshing as taking a walk in the woods" in his vision on ubiquitous computing $[17,89]$.

The lens highlights the benefits of lone exercising, as such, it sharpens our perspective onto the social aspects of exertion (and the lack thereof). The importance of the social dimension of exertion has been previously highlighted [57], here we use it to unpack reverie further: Reverie can emerge from lone exercising from within (Void), from a lack of social stimulation (Solitude) and from a change of social scenery (Mini-holiday).

\section{Void}

Reverie can emerge from lone exercising which offers the opportunity to experience a "void": a state of mind characterized by a lack of calculative awareness, diffuse attention, and fleeting ideas and perceptions. This mind state provides a healthy opportunity to avoid concentration - an idle mind, without some of the pathological effects of pharmaceuticals.

\section{Technology consideration}

We find that designers have a particular opportunity to regulate the amount of stimulation in order to support the emergence of a void. People's senses and motor skills are most alive in interplay with a tactile vibrant environment. This involvement with a constantly changing environment serves to enrich people's perception [91,p.29] but can also be detrimental to the emergence of a void. For example, many joggers who run in urban areas use headphones in order to reduce the amount of stimulation coming from the busy environment. Similarly, running through a busy city center might provide too much stimulation for a void to emerge; in response designers might want to think about the use of jogging AR [83] not to provide even more information (like jogging AR glasses currently do in the form of presenting heart rate, speed etc.), but rather use AR glasses to block out certain parts of the built environment in order to facilitate the emergence of a void (similar to the system that blocks out advertisement displays in an urban environment [15]). On the other hand, joggers on treadmills often use TV and even virtual worlds (such as virtual running routes [22]) to increase the amount of stimulation. We highlight that technology offers an opportunity to sense any outside stimulation and in response could in real-time adjust any digital stimulation in order to dynamically facilitate the emergence of a void.

In our own work [58, 60] with joggers who have used headsets to listen to their remote jogging partner's breathing, we have found that void has emerged, as the soothing breathing functioned in a similar way as the sound of waves from the ocean can facilitate the emergence of void. This was supported by the headsets that blocked out much of the surrounding sounds and the microphone being close to the mouth that amplified the breathing sounds. Of course designers need to be aware of any safety implications when moderating such external stimulation: for example, blocking out external noise was ok in this work as the joggers were running in a park, however, it might have posed a safety risk if joggers would have been running on roads where they need to hear approaching cars.

\section{Solitude}

It has been shown that technology can enable new ways of exercising together, for example, by allowing people to exercise over a distance [60] or over time [80]. Contrasting this, the reverie lens highlights that there is also benefit to solitude: being alone can be refreshing sometimes, which can be achieved by simply "walking away".

\section{Technology consideration}

Most apps that support walking or jogging proudly feature social integration, often to enable competitions [9, 16, 42]. However, the notion of solitude highlights that there is also benefit to being alone (even virtually), and we encourage designers to think about how to facilitate the emergence of solitude, such as celebrating solitude by making users aware that they are alone and remind them that this is an opportunity to relax. The system would highlight that solitude is a desirable state, rather than simply a lack of social relatedness (see notifications such as "0 followers" that suggest one does not have enough friends). Furthermore, the system could also actively support solitude by, for example, turning off all notifications to increase the chances of reverie to emerge.

We are aware that highlighting solitude can also pose dangers. In "jogging over a distance" [60], participants, especially females, applauded that the audio connection to remote joggers gave them a sense of not being alone, which provided feelings of safety, especially at night in public parks. As such, designers have a particular responsibility to 
manage solitude against a perceived risk of danger, in particular during exertion alone outside.

\section{Mini-holiday}

Reverie can also come in the form of a mini-holiday from the everyday, helping people to let go of the social pressures and concerns that occur during everyday "regular" life. In other words, as day-to-day life is filled with responsibilities and tasks, exertion activities can provide a welcoming reprieve. Like holidays are valued because of their experiential characteristic, exertion activities are also not just instrumental means to reach specific objectives, such as health goals. We highlight that reverie can prove a reprieve from everyday life, offering users a mini-holiday.

\section{Technology consideration}

Designers who want to support reverie can utilize the notion of mini-holiday by contrasting the exertion experience with everyday life. Technology can be useful here, as most people engage technology to manage their everyday life. For example, an interactive system could pull data from a user's work calendar to point out how a scheduled exertion activity is different to his/her everyday life. This allows for a more personalized experience as it provides contrasting moments that are context-dependent [4]: for example, by highlighting how evening exertion activities might be a welcoming physically reprieve for an office employee; however, this might be different for a laborer with a physically demanding job. We point out that such context-aware systems come with an integration of data from "work-life" to "holiday-life", which might pose privacy issues that some users might not be comfortable with, so this needs to be carefully managed.

\section{Exercise tip}

Go for a walk outside after reading this paper and see what additional new thoughts this offers to your research.

\section{LENS 2: PLEASURE}

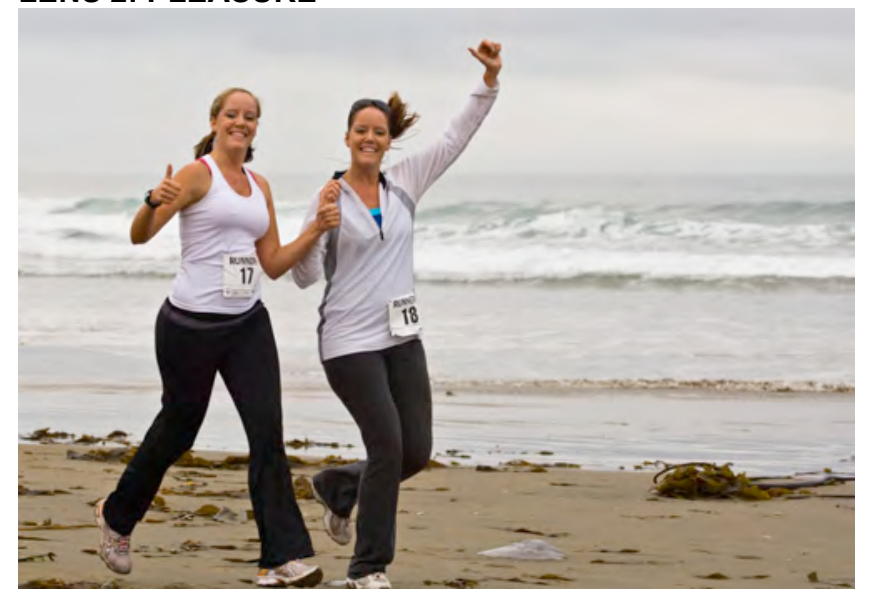

Fig. 2. Pleasure from, in, and of exertion
There are many ways how exertion activities can facilitate feelings of pleasure, for example pleasure can come from receiving medals in front of an audience, from having achieved a personal best or from being selected to be part of a higher league team. Interactive systems have helped facilitate these feelings of pleasure, in particular game mechanics utilized under the term gamification, such as ladders, badges and high score tables, have been used. However, we highlight that there are additional ways of how pleasure can be facilitated, in particular through the felt experience [28] of extensively engaging one's body during exertion activities, right after and over longer periods: firstly, through the pleasure arising from discomfort during an activity (Pleasure from discomfort) and secondly through experiencing pleasure in oneself after an extensive workout (Pleasure in oneself), and thirdly through enjoying a firmer self as a result of repeated exercise (Pleasure of a firmer I).

\section{Pleasure from discomfort}

Many of everyday life experiences require caution, with social norms demanding to restrain aggressive urges and the letting off of steam. This restraining of aggressive urges seems to be particularly prevalent in today's office environments, where interacting with computers often leads to frustration. Exertion activities, especially short, intense components of it, such as sprints, are the antithesis to this. They have a purity to them that is very simple and affords a single-mindedness that does not allow for second-guessing [91,p.38]. These intense, primal components of exertion activities enable participants to experience a change from the thinking part of what constitutes being in most of today's society. This primal aspect of fully exerting oneself comes with a sense of discomfort, however, this can also counterintuitively facilitate a sense of pleasure.

\section{Technology consideration}

We find that the exhaustion agony or even nausea that comes from intense exertion activity is rarely considered or even promoted by interactive technology. In particular, exertion console games have been criticized for only supporting "mild" exertion [56], juxtaposing them against traditional sports with their intense exertion actions. Part of this can be attributed to the fact that most technologies are still rather fragile and not designed to be able to handle intense physical activity, in response, research around "brute force" interfaces [51, 61] has emerged to change this.

\section{Pleasure in oneself}

Hume says that pride is pleasure in oneself, helping people to show they are valuing the right things [30]. Pleasure in oneself has two aspects to it; the first is the cause of pleasure, for example muscular arms after having been to the gym. The second aspect is the object people attribute to themselves, which is seeing oneself as being more attractive because of the toned arms. 


\section{Technology consideration}

Social media technology allows people to take pictures of their toned arms (they can even use filters that make the arms look more toned, highlighting the cause of pleasure) after a workout and send it to a large number of followers in order to hear how many people find these arms attractive. Without the help of technology, reaching a large number of people to fuel such pleasure would be much more difficult to achieve. However, such pleasure in oneself can lead to narcissism, especially with the ability of technology to reach a large number of people, and should therefore be carefully designed [75].

\section{Pleasure of a firmer "|"}

Exertion activities not only help to tone muscles, but also establish a firmer idea of oneself, allowing "to impress upon the world the stamp of one's own existence" [91]. This firmer idea of oneself is not what people see when they look at themselves in the mirror, but rather the "I" as the "me-self" [25]. People cannot see this "me-self", however, they have a mental idea of it: Young [91] explains that when people engage in exertion activities, the fact that people see, feel and experience the pedaling, pushing, pulling and so forth helps them to infer with more solidity that they are contributing towards the building of the "meself", reaching a firmer idea of themselves.

\section{Technology consideration}

The pleasure of a firmer "I" reminds us of Wii tennis: the remarkable achievement of Wii tennis was not that it let people train tennis and therefore supported them in being better tennis players, but rather that it supported players in believing that they could become better tennis players by allowing them to act out what they believed were movements tennis players would do [7]. Berthouze et al.'s research showed the potential of interactive technology to support this: in an experiment, players of Guitar Hero who were encouraged to move more (through the star-power mechanic) believed they were more likely to be able to become rock stars than those who did not move [6]. In order to facilitate this, the technology utilized fantasy elements (such as visuals of a concert stage and audio from a cheering crowd, etc.) in order to support the idea of a firmer "I". So the combination of technology and exertion can aid people to physically act out their desires for a better "I" while helping visualize what this better "I" experience could look like.

\section{Exercise tip}

Try to run as fast as you can, for as long as you can. Are you experiencing pleasure from, pleasure in, or pleasure of something?

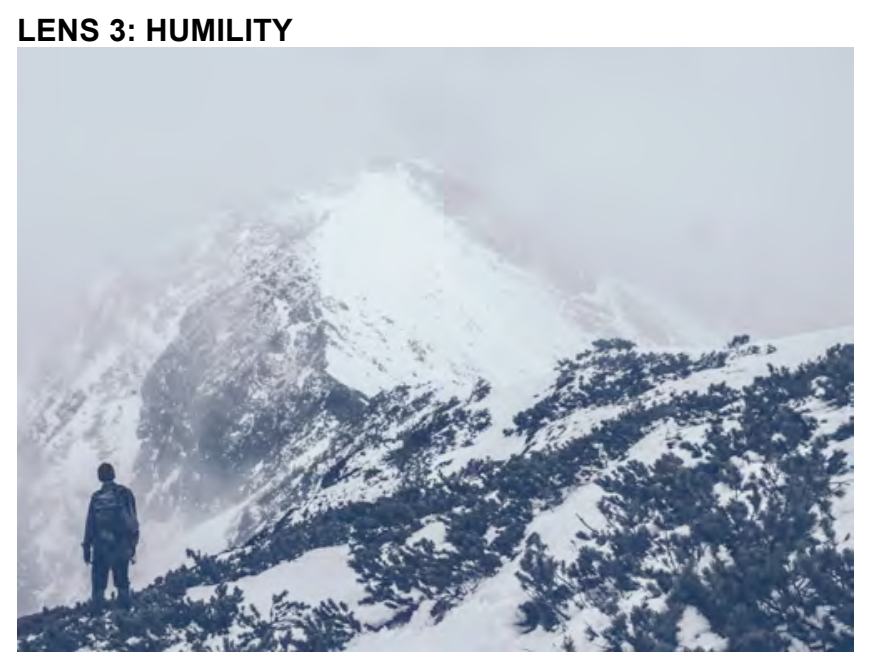

Fig. 3. Humility teaches honesty with oneself

Humility refers to people's awareness of their own (bodily) flaws and limitations. People can feel humble because they perceive some ugliness in themselves that makes them uncomfortable and unpleasant. This humility is heightened when exercising with others who are superior, as it demonstrates a not-so-favorable version of oneself. As such, the lens of humility teaches a person about his/her own fragility, and thereby encourages improvement. The previous lens pleasure works well in collaboration with humility: when pleasure pushes on, humility pulls back, helping people to succeed by highlighting both drive and caution.

We identify 3 ways how humility can be facilitated: by becoming aware of one's own bodily limitations, by the physical environment, and by failing and trying again.

\section{Awareness of one's own bodily limitations}

In humility, people can find greater honesty, which gives them a new responsibility for living. Participants experience more of their "true" abilities, not what they imagine or their environment tells them they can do. Only if exertion is involved, can people physically experience the limitations of their own bodies, and as such these limitations become more real and help people be more honest with themselves. Once people are aware of their own bodily limitations, the resulting humility can help to improve.

\section{Technology consideration}

The potential for technology to facilitate awareness of bodily action as part of augmented exertion experiences has been previously highlighted [57]. Here we add that technology offers unique opportunities to allow for novel comparisons as a way to become aware of one's own bodily limitations. This includes:

- comparisons with expert sportspeople who otherwise might not be accessible: for example, an avid runner might not have the opportunity to run with other, similar advanced runners. Technology can enable running with avid runners all over the world (for example through 
systems such as [59, 71]), allowing even advanced runners to experience humility by seeing how many people are better. However, designers need to be careful: comparisons with too many people who are better can be demotivating as humility requires an honest assessment of one's shortcomings in order to utilize it as motivator to strive for better.

- comparisons with oneself. Technology allows for easy tracking of personal achievements (as promoted by the quantified self movement [48]), hence allows for identifying one's shortcomings compared to not just yesterday, but a year or ten years ago. This might help in being more honest about one's aging and realizing that over the years, different efforts are needed to nurture and cultivate one's body.

\section{Environment features as lie detectors}

Exercising with others can facilitate a sense of meekness as a result of feeling humble, however, people can also "yell them down": people can use their minds to intimidate others to distract from their own limitations in order to not experience a sense of humility. In contrast, if people experience humility through the physical environment (such as a massive cliff face during rock climbing), they cannot "yell it down" or intimidate it. The rock face is not only indifferent, it is also unstable and shows how fragile people are in comparison, providing opportunities to experience a sense of humility. This is the reason why climbers treat the Eiger's north face as a "lie detector", as such humiliating environmental features prompt brutal honesty: you recognize the terrain and weather, or you die.

\section{Technology consideration}

Imposing cliff faces are examples of physical environment features that cannot be yelled down and therefore function as personal lie detectors. Such cliff faces also exist in digital form, for example in virtual reality rock-climbing systems [13]. However, designers need to be aware that with these digital counterparts, users can always "explain" any of their bodily limitations by referring to the VR world not being programmed right or experiencing bugs in the code. Therefore, VR environments cannot function as lie detectors to the same extent as the physical environment, suggesting that virtual climbing experiences do not hold the same potential to facilitate a sense of humility as augmented climbing walls (such as [33]). How to foster humility in VR environments is therefore an important area of future research.

\section{Failing and trying again for its own sake}

Mountaineer George Mallory is believed to have replied to the question "Why did you want to climb Mount Everest?" with the retort "Because it's there" [11]. His quote highlights that engaging in exertion activities can have a self-purpose and enjoyed for its own sake. Csikzentmihaly [14] calls this "autotelic" and stresses that achievement requires both, ambition and failure. People do not overcome their insufficiencies by just thinking about them, they have to $d o$, reflect on them, and then try again. Humility means people recognize that they are incomplete, and always will be, and any attempts to fail and try again are enjoyable for their own sake, not because people know they will achieve perfection.

\section{Technology consideration}

We find that technology has been emerging that can help people see (and feel) their own failings and how they relate to a challenging world in particular through safety equipment and clothing that supports outdoor adventure activities [2]. These technologies do not aim to reduce the recognition that people are fragile and navigate indifferent and unstable environments (unlike many VR experiences that aim to make adventure "safe"), but rather, they try to enrich the experience by providing participants with a safety net that allows them to try out things that otherwise might simply paralyze them. For example, safety gear allows rock climbers to attempt moves with the knowledge that they can fail and try again, offering an opportunity to acknowledge one's insufficiencies. The payoff is a sped-up experience of skillful striving.

Although safety gear has significantly benefited from technology in recent years (for example, climbing gear has become more robust and lighter, allowing for more difficult and longer routes), the inclusion of interactive technology is only emerging (as suggested by $[2,87]$ ) and we find this an intriguing area for future research.

\section{Exercise tip}

Try out an exertion activity that is completely new to you. Do you experience a sense of humility?

\section{LENS 4: SUBLIME}

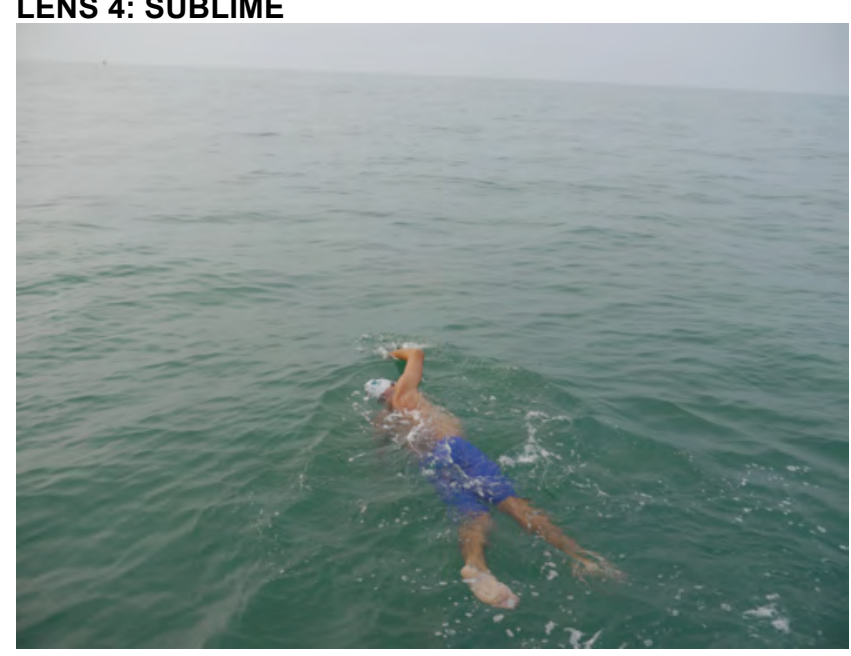

Fig. 4. Fearful joy during open-ocean swimming

The sublime is elicited from the feeling of fearful joy. A typical sport that encourages the sublime is swimming, which can cultivate fear with the size and power of the water, yet does so safely and with some emotional distance. We highlight the following 3 facets of the sublime: putting 
the body in and out of control, stimulation by threat and allowing people to savor the precariousness of life.

\section{In and out of control}

A key aspect that evokes the sublime is the body being in and out of control. For example, the water accommodates the open-ocean swimmer, but also shakes and submerges him/her. The swimmer senses danger and feels the precariousness of their body in the enormous body of water, yet she/he is afloat, directing oneself, responding to the waves and tidal forces. This encourages a sense of what we call the sublime: a kind of thrilled terror.

\section{Technology consideration}

Technology can facilitate in and out of bodily control experiences, for example, prior work [53] has used breathing sensors to control a fairground bronco ride in order to allow riders to be in and out of bodily control: if they were breathing too much, the bronco would throw them off, taking bodily control, but if the riders were holding their breath, they were in control, however, they could only hold their breath for so long. Designers can use more than just mechanical devices - such as fairground rides - to facilitate the sublime: recent work [8] suggests that galvanic vestibular systems that digitally control a person's sense of balance through electrodes attached behind the ear can also enable in and out of bodily control experiences. We see these internal interface mechanisms as compelling opportunities to facilitate future novel sublime experiences.

\section{Stimulation by threat}

Exertion activities that evoke the sublime require both enjoyment and fear; for example, swimming reveals just how vulnerable people are (if they would stop swimming, they would drown), yet people enjoy the buoyancy. The point is not that the sea actually drowns people but rather that it could. This vulnerable aliveness arises only if both feeling vulnerable and feeling alive are in balance: a novice swimmer will simply feel panic in a choppy ocean, while a competent swimmer will not feel vulnerable in a local pool.

\section{Technology consideration}

Prior work has stressed the potential of technology to "balance" exertion experiences [5, 21, 58]; here we extend this work by pointing to the potential of technology to balance between feeling vulnerable and feeling alive in order to increase the chances for the sublime to be evoked. For example, if sensors could detect that a competent swimmer in a shallow pool is too comfortable to experience a sensation of sublime, it could use displays installed at the bottom of the pool to make the pool look deeper and more precarious like the ocean, or with a movable pool floor, the system could increase the depth of the pool while a wave machine creates a current. Similarly, if a novice swimmer already feels vulnerable in the pool, the system could detect this through indicators such as hectic movements and in response heighten the pool floor.

\section{Savoring the precariousness of life}

The sublime highlights people's unique relation to the world: separated enough to see it as something "other", attached enough to be moved and shaken. By threatening in a safe way, the world stimulates, and by keeping people secure, it allows them to enjoy this stimulation. Exertion activities, in this, are a chance to savor the precariousness of life [91]. Perhaps they also encourage gratitude: a heightened awareness of life, which recognizes its vulnerability and beauty.

\section{Technology consideration}

Technology can support the savoring of the precariousness of life by highlighting that people have limitations, yet they are secure and part of something bigger: the work by Hamalainen et al. [23] illustrates this nicely by suggesting gravity as a design tool for exertion activities: gravity, although people constantly struggle with it (in their example in a skydiving simulator), it keeps them secure (they know they will not fly “off”), whilst not discriminating (everyone is affected by gravity). The authors propose that mixed-reality environments can facilitate novel experiences around gravity (for example through interactive skydiving harnesses), and we believe such augmented experiences offer people new ways to taste the precariousness of life, ultimately evoking the sublime.

\section{Exercise tip}

If you live nearby, go swimming in the ocean, and think about how deep it is below you, appreciate the fear that arises from it, but also what you feel from the recognition that you can easily reach the shore.

\section{LENS 5: ONENESS}

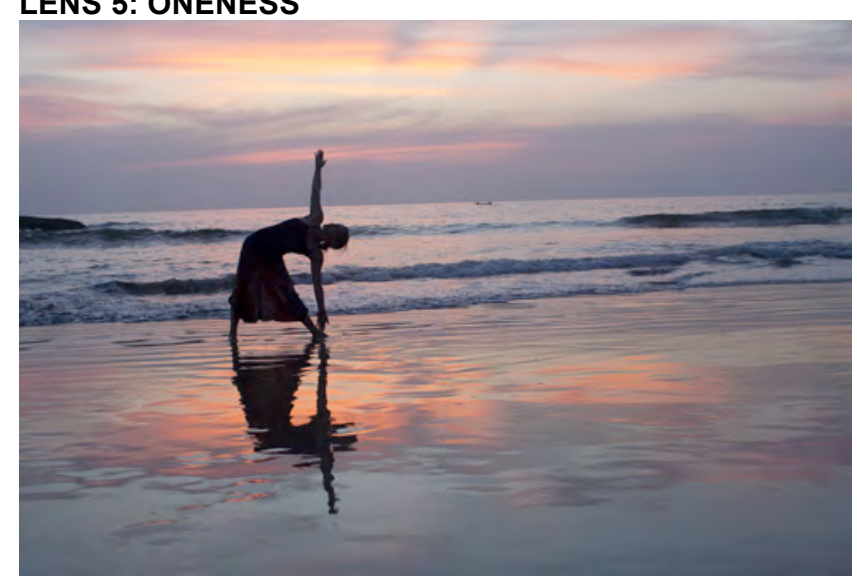

Fig. 5. Yoga at sunrise to reach oneness

The oneness lens helps focus on the benefit of encouraging intimate familiarity with one's own body, and "then transcend this with an impression of 'oneness' with the world" [91]. Whereas the previous lenses focused on shaping the "I", the oneness lens refers to a brief liberation from the burden of being an "I". It complements the other lenses by helping to get the focus away from the "I" and see the self as part of a bigger whole. 
A typical activity is yoga: oneness derived from yoga has been described as like "coming home after a long holiday, and looking at one's house anew - only the house is me" [91]. Yoga can rekindle a familiarity of one's body by making conscious what is usually unconscious, yet this is not externally (such as discovering a spot on one's skin) but rather kinesthetically from within. Exertion activities can therefore allow people to gain a vivid picture of their own body, but it is not just a mirror where one can see one's body, it is also a felt experience: it is a felt picture of one's body. This can also promote the opposite: losing oneself in one's own body, allowing for a "brief emancipation from the experience of ourselves" [91].

We believe seeing exertion through a lens of oneness will become more and more important as many people, especially those working in office environments, have turned to activities such as yoga to deal with today's stresses. Prior work suggests that these practices can offer mental health benefits [77], and we believe technology has the potential to further that [28]. In order to guide such developments, we highlight that oneness develops over time (borrowing from the fact that time plays a heightened role in exertion activities [52, 57]): First, oneness supports developing a heightened awareness of one's own bodily practices, which in consequence helps people feel at home in their own bodies. Then, over time, oneness facilitates experiencing one's own body as a bodily record of one's life experiences.

\section{Heightened awareness of one's own bodily practices}

One facet of oneness that is particularly enabled through the slow movements and stretching activities of yoga is the ability to allow people to perceive a heightened sensation of their own bodily practices and the lifestyle they reflect. These exercises can help people become more aware of the incidents and accidents (for example, a replacement joint affects the type and quality of movements one can do) that define them, helping people to better comprehend themselves as physical, psychological and social beings.

\section{Technology consideration}

Research around technology that supports a heightened sensation of one's own bodily practices is only emerging, but represents an increasing trend. We note that most current systems aim to highlight practices and lifestyles that are considered unhealthy and in consequence focus on remedy. For example, the "slouch device" [47] is targeted at office workers prone to back pain: it is a small wearable sensor that alerts through vibration when the user is engaging in bad posture by sensing a slouching position. We believe such technology could also be used to heighten the sensation of one's bodily practices in order to not only rectify unhealthy practices, but rather help people feel more like themselves. For example, we believe emerging sensors such as breathing devices [53] could facilitate a heightened sensation of people's own breathing practices and associated lifestyles, and in consequence help them feel more like themselves.

\section{Making ourselves at home in our bodies}

Through this heightened awareness of one's own bodily practices people can experience a richer conception of themselves, like an imaginary internal world that portraits the normally hidden architecture of muscles, bones, joints, etc. Young [91] says: "This increased sensitivity to one's body is also a mental exercise, a labor of imagination and a creative act." Through exertion activities, people are making themselves at home in their bodies, allowing themselves to become comfortable in their own bodies - or more aware of the forces making them uncomfortable. In particular if movements are unusual, such as slow moving and stretching, they can nudge people to become more intimate with their own body. While activities such as bodybuilding build the body from the outside, yoga does it from the inside.

\section{Technology consideration}

When it comes to opportunities to make oneself at home in one's body, "health games" come to mind that allow people to "look inside" their bodies, helping people understand what is going on when being sick, often used in a hospital context [34]. One of the features of these games is that they can include fantasy elements: for example, such games allow children with cancer to "look inside" their bodies in order to experience a cartoon-like fantasy world inside their bodies that depict how their medications attack "bad" cells in order to teach the children why it is a prolonged process in which the child needs to actively participate in. However, so far, such games do not involve any bodily activity (although this is important even in hospitals [3]). We believe advanced sensor systems can change this in the future, for example, we can envision an augmented reality system that allows people to "see" how their muscles engage during rehabilitation exercises to help people make themselves at home in their bodies, as frail and injured as they might be (extending medical science teaching with AR versions of the human body [81]).

\section{Bodily record}

Once people have a heightened sensation of their own bodily practices and made themselves at home in their own bodies, oneness facilitates experiencing the body as a fleshy record: how a person walks and runs, what his/her posture is and the various ways she/he gestures is unique to a person and demonstrates individual quirks and a unique upbringing. The body can therefore be seen as a public display of one's joys and anxieties as well as any public achievements and failures. This explains the appeal of tattoos, as people use them to tell the story behind this record. And as the body ages, this record ages along with it, showing signs that are highly visible and are often worn with pride of a life full of experience. The notion of bodily record is not only applicable to a sports contexts: for instance software that previously only focused on people's 
faces to reliably identify individuals is now also analyzing gait as it forms part of one's unique bodily record [88].

\section{Technology consideration}

In recent years, projects have begun to emerge that relate to the notion of the body as a fleshy record. For example, work by Lo et al. [44] showed electronic circuits that are directly attached onto the skin, allowing for electronic tattoos that enable new and richer forms of displays of fleshy records. These displays could react to the wearer's immediate bodily actions, allowing for new ways of telling stories behind - and with - a bodily record. The notion of fleshy record is also visible in the current trend of prostheses that are not aiming to look like real limbs, but rather high-end technology devices. Wearers showcase their high-end prosthesis publicly and dress them along with their outfits [41] rather than hiding them, utilizing the wearable technology as part of their fleshy record.

Although these works demonstrate the potential of technology to support the notion of fleshy record, there are still many unresolved issues: although technology can now deal much better with the malleability of human skin, recent examples [44] highlight that the storage and replacement of batteries as part of these fleshy records is still a challenging problem, as is washing and cleaning.

\section{Exercise tip}

Listen "inside" your body: which muscles are tense right now while you are reading this, which body parts are underused and overused?

\section{DISCUSSION AND CONCLUSION}

HCI advancements have recently emerged that support the physically active human being, however, new work suggested that the field has only begun to facilitate the many virtues of exertion. To further the field, we introduced a set of lenses, grounded in the literature of sports philosophy, to help designers see exertion not just as a means of deferring death, but also as an opportunity for personal growth. Using these lenses, we articulated associated technology opportunities and also presented practical exertion activities the reader can engage in or use as part of teaching our work to others.

As our work is only a starting point towards expanding the perspectives through which exertion experiences can be examined, we acknowledge that our work has limitations. One limitation is that we have not yet full considered how other people might be impacted when technology supports people being physically active as proposed by our lenses. Those effects will have implications on the exertion experiences in return, informing iterations of our lenses.

We hope our work serves as springboard for future investigations. One immediate avenue could be workshops with designers who would engage with the lenses in order to develop new exertion systems. However, it should be noted that it is not meant for the lenses to be considered to the same extent across every exertion system, but rather, they aim to focus the eye onto specific perspectives of exertion.

Future work might also include further considerations of people with bodies that are beyond the "common" norm, such as people with injuries or disabilities. Such investigations will contribute to the ethical discourse on the emerging body-centric HCI future, as many bodily activity sensing devices currently exclude a large number of people simply because these devices fail to adequately sense them.

We see our work reflecting the earlier HCI call for action to "go beyond" [27]: we aim to not just replicate existing exertion experiences (such as simulating sports in VR), but rather to use technology to go beyond what we can currently envision in terms of exertion experiences. We hope our lenses provide a scaffold for inspiration. Furthermore, by proposing lenses based on ethical philosophy, our work is related to value sensitive design, which has previously successfully used ethical philosophy to guide the design of exertion support technology [20]. As such, we see our work also contributing to the call for a more ethics-sensitive HCI future that considers and supports human's values when designing interactive systems [24]. We hope with our work, we are able to aid the HCI community in considering the many virtues of exertion and in consequence develop better interactive systems to support people being physically active.

In summary, our work aims to contribute to the emerging HCI area of designing for exertion experiences. We find that for a combination of bodily exertion and interactive experiences to be successful and truly go beyond what is currently available, we need a thorough understanding of the multiple perspectives of not simply having, but being an active human body. We hope with our work in the form of a set of lenses guided by sports philosophy, we are able to support designers with a starting point to consider these multiple perspectives, aiding in facilitating the many virtues of exertion so that ultimately more people profit from the many benefits of being physically active.

\section{ACKNOWLEDGEMENTS}

Florian 'Floyd' Mueller appreciates the support from the Australian Research Council (DP110101304\&LP130100743). We thank the reviewers, the members of the Exertion Games Lab and Patrick Baudisch's group for their feedback, especially Sebastian Marwecki, Thijs Roumen, Pedro Lopes and Alan Borning. We also thank the photographers: Reverie: (C) 2013 Kari Quaas; Pleasure: Mike Baird (flickr.com/photos/mikebaird/2913346926); Oneness: Dennis Yang (/dennis/11500905496); Sublime: Adam Thornton (/gratitudepics/15173981841). 


\section{REFERENCES}

1. Sensoria Fitness. Retrieved September 1, 2016 from http://www.sensoriafitness.com/.

2. Florian Mueller and Sarah Jane Pell. 2016. Technology Meets Adventure: Learnings from an Earthquake-Interrupted Mt. Everest Expedition. In Proceedings of the 2016 ACM International Joint Conference on Pervasive and Ubiquitous Computing (Ubicomp'16). ACM, 817-828. http://dx.doi.org/10.1145/2971648.2971683

3. Ruth Sancho Huerga, Jennifer Lade and Florian Mueller. 2016. Designing Play to Support Hospitalized Children. In Proceedings of the 2016 Annual Symposium on Computer-Human Interaction in Play (CHI PLAY'16). ACM, 401-412. http://dx.doi.org/10.1145/2967934.2968106

4. Gregory D Abowd, Anind K Dey, Peter J Brown, Nigel Davies, Mark Smith and Pete Steggles. 1999. Towards a Better Understanding of Context and Context-Awareness. In Proceedings of the International Symposium on Handheld and Ubiquitous Computing. Springer, 304-307.

5. David Altimira, Florian Mueller, Jenny Clarke, Gun Lee, Mark Billinghurst and Christoph Bartneck. 2016. Digitally Augmenting Sports: An Opportunity for Exploring and Understanding Novel Balancing Techniques. In Proceedings of the 2016 CHI Conference on Human Factors in Computing Systems (CHI'16). ACM, 1681-1691. http://dx.doi.org/10.1145/2858036.2858277

6. Nadia Bianchi-Berthouze. 2013. Understanding the Role of Body Movement in Player Engagement. Human-Computer Interaction 28, 1: 40-75.

7. Ian Bogost. 2006. Persuasive Games: Wii's Revolution Is in the Past. Retrieved September 1, 2007 from http://www.seriousgamessource.com/features/feature 112806_wii_1.php

8. Richard Byrne, Joe Marshall and Florian Mueller. 2016. Designing the Vertigo Experience: Vertigo as a Design Resource for Digital Bodily Play. In Proceedings of TEI '16: Tenth International Conference on Tangible, Embedded, and Embodied Interaction (TEI'16). ACM, 296-303. http://dx.doi.org/10.1145/2839462.2839465

9. Sunny Consolvo, David W. McDonald, Tammy Toscos, Mike Y. Chen, Jon Froehlich, Beverly Harrison, Predrag Klasnja, Anthony LaMarca, Louis LeGrand, Ryan Libby, Ian Smith and James A. Landay. 2008. Activity Sensing in the Wild: A Field Trial of Ubifit Garden. In Proceedings of the SIGCHI Conference on Human Factors in Computing Systems
(CHI'08). ACM, 1797-1806.

http://dx.doi.org/10.1145/1357054.1357335.

10. Sunny Consolvo, Predrag Klasnja, David W McDonald and James A Landay. 2012. Designing for Healthy Lifestyles: Design Considerations for Mobile Technologies to Encourage Consumer Health and Wellness. Human-Computer Interaction 6, 3-4: 167315.

11. Wikipedia contributors. 2016. George Mallory Wikipedia, the Free Encyclopedia. Retrieved September 1, 2016 from https://en.wikipedia.org/w/index.php?title=George_M allory\&oldid $=738677523$.

12. Eka Peng Cox, Nicholas O’Dwyer, Rebecca Cook, Melanie Vetter, Hoi Lun Cheng, Kieron Rooney and Helen O’Connor. 2015. Relationship between Physical Activity and Cognitive Function in Apparently Healthy Young to Middle-Aged Adults: A Systematic Review. Journal of Science and Medicine in Sport 19, 8: 616-628.

13. Crytek. 2016. The Climb. Retrieved September 1, 2016 from http://www.theclimbgame.com.

14. Mihaly Csikszentmihalyi. 1990. Flow: The Psychology of Optimal Performance. New York: Harper and Row.

15. Anthony Cuthbertson. 2015. Brand Killer: Augmented Reality Goggles Create Real-World Adblock.

Retrieved September 1, 2016 from http://www.ibtimes.co.uk/brand-killer-augmentedreality-goggles-create-real-world-adblock-1484844.

16. Rodrigo de Oliveira and Nuria Oliver. 2008. Triplebeat: Enhancing Exercise Performance with Persuasion. In Proceedings of the 10th international conference on Human computer interaction with mobile devices and services. ACM, 255-264. http://dx.doi.org/10.1145/1409240.1409268

17. Anind Dey. 2016. Where the *\#*\$\% Is My Walk in the Woods? Ubicomp'16 Plenary Talk.

18. Arne Dietrich. 2006. Transient Hypofrontality as a Mechanism for the Psychological Effects of Exercise. Psychiatry Research 145, 1: 79-83. http://dx.doi.org/10.1016/j.psychres.2005.07.033

19. Paul Dourish. 2001. Where the Action Is: The Foundations of Embodied Interaction. MIT Press.

20. Daniel A Epstein, Alan Borning and James Fogarty. 2013. Fine-Grained Sharing of Sensed Physical Activity: A Value Sensitive Approach. In Proceedings of the 2013 ACM international joint conference on Pervasive and ubiquitous computing. ACM, 489-498. http://dx.doi.org/10.1145/2493432.2493433 
21. Kathrin Maria Gerling, Matthew Miller, Regan L Mandryk, Max Valentin Birk and Jan David Smeddinck. 2014. Effects of Balancing for Physical Abilities on Player Performance, Experience and SelfEsteem in Exergames. In Proceedings of the SIGCHI Conference on Human Factors in Computing Systems (CHI'14). ACM, 2201-2210.

http://dx.doi.org/10.1145/2556288.2556963

22. Jonna Häkkilä, Leena Ventä-Olkkonen, Henglin Shi, Ville Karvonen, Yun He and Mikko Häyrynen. 2013. Jogging in a Virtual City. In Proceedings of the 12th International Conference on Mobile and Ubiquitous Multimedia. ACM, 50.

http://dx.doi.org/10.1145/2541831.2541881

23. Perttu Hamalainen, Joe Marshall, Raine Kajastila, Richard Byrne and Florian Mueller. 2015. Utilizing Gravity in Movement-Based Games and Play. In Proceedings of the 2015 Annual Symposium on Computer-Human Interaction in Play (CHI PLAY'15). ACM, 67-77. http://dx.doi.org/10.1145/2793107.2793110

24. Richard Harper, Tom Rodden, Yvonne Rogers and Abigail Sellen. 2008. Being Human: Hci in the Year 2020. Microsoft Research.

25. Susan Harter. 2015. The Construction of the Self: Developmental and Sociocultural Foundations. Guilford Publications.

26. Eric B Hekler, Predrag Klasnja, Jon E Froehlich and Matthew P Buman. 2013. Mind the Theoretical Gap: Interpreting, Using, and Developing Behavioral Theory in Hci Research. In Proceedings of the SIGCHI Conference on Human Factors in Computing Systems (CHI'13). ACM, 3307-3316. http://dx.doi.org/10.1145/2470654.2466452

27. Jim Hollan and Scott Stornetta. 1992. Beyond Being There. In CHI '92: Proceedings of the SIGCHI conference on Human factors in computing systems (CHI'92). ACM Press, 119-125. http://dx.doi.org/10.1145/142750.142769

28. Kristina Höök, Martin Jonsson, Anna Ståhl and Johanna Mercurio. 2016. Somaesthetic Appreciation Design. In Proceedings of the SIGCHI Conference on Human Factors in Computing Systems (CHI'16), .ACM, 3131-3142. https://doi.org/10.1145/2858036.2858583

29. Kristina Hook, Anna Stahl, Martin Jonsson, Johanna Mercurio, Anna Karlsson and Eva-Carin Banka Johnson. 2015. Somaesthetic Design. interactions 22, 4: 26-33. http://dx.doi.org/10.1145/2770888

30. David Hume. 2012. A Treatise of Human Nature. Courier Corporation.
31. Caroline Hummels, Kees C. Overbeeke and Sietske Klooster. 2007. Move to Get Moved: A Search for Methods, Tools and Knowledge to Design for Expressive and Rich Movement-Based Interaction. Personal and Ubiquitous Computing 11, 8: 677-690.

32. Katherine Isbister and Florian Mueller. 2014. Guidelines for the Design of Movement-Based Games and Their Relevance to HCI. Human-Computer Interaction 30, 3-4: 366-399. http://dx.doi.org/10.1080/07370024.2014.996647

33. Raine Kajastila, Leo Holsti and Perttu Hämäläinen. 2016. The Augmented Climbing Wall: High-Exertion Proximity Interaction on a Wall-Sized Interactive Surface. In Proceedings of the 2016 CHI Conference on Human Factors in Computing Systems (CHI'16). ACM, 758-769. https://doi.org/10.1145/2858036.2858450

34. Pamela M Kato, Steve W Cole, Andrew S Bradlyn and Brad H Pollock. 2008. A Video Game Improves Behavioral Outcomes in Adolescents and Young Adults with Cancer: A Randomized Trial. Pediatrics 122, 2: e305-e317.

35. Rohit Ashok Khot, Larissa Hjorth and Florian Mueller. 2014. Understanding Physical Activity through 3d Printed Material Artifacts. In Proceedings of the SIGCHI Conference on Human Factors in Computing Systems (CHI'14). ACM, 3835-3844. http://dx.doi.org/10.1145/2556288.2557144

36. Rohit Ashok Khot, Jeewon Lee, Deepti Aggarwal, Larissa Hjorth and Florian Mueller. 2015. Tastybeats: Designing Palatable Representations of Physical Activity. In Proceedings of the 33rd Annual ACM Conference on Human Factors in Computing Systems (CHI'15). ACM, 2933-2942. http://dx.doi.org/10.1145/2702123.2702197

37. Predrag Klasnja, Sunny Consolvo and Wanda Pratt. 2011. How to Evaluate Technologies for Health Behavior Change in Hci Research. In Proceedings of the SIGCHI Conference on Human Factors in Computing Systems (CHI'11). ACM, 3063-3072. http://dx.doi.org/10.1145/1978942.1979396

38. Scott Klemmer and Bjorn Hartmann. 2006. How Bodies Matter: Five Themes for Interaction Design. In Proceedings of the 6th conference on Designing Interactive systems (DIS'06). ACM, 140-149. https://doi.org/10.1145/1142405.1142429

39. Robert Scott Kretchmar. 2005. Practical Philosophy of Sport and Physical Activity. Human Kinetics Publishers (Champaign, IL, USA).

40. Kylie Ladd. The Unexpected Idea. Retrieved September 1, 2016 from https://griffithreview.com/articles/the-unexpectedidea/. 
41. Richard E. Ladner. 2015. Design for User Empowerment. interactions 22, 2: 24-29. http://dx.doi.org/10.1145/2723869

42. James Lin, Lena Mamykina, Silvia Lindtner, Gregory Delajoux and Henry Strub. 2006. Fish'n'steps: Encouraging Physical Activity with an Interactive Computer Game. In Proceedings of UbiComp 2006: Ubiquitous Computing. ACM, 261-278. https://doi.org/10.1007/11853565_16

43. Conor Linehan, Sabine Harrer, Ben Kirman, Shaun Lawson and Marcus Carter. 2015. Games against Health: A Player-Centered Design Philosophy. In Proceedings of the 33rd Annual ACM Conference Extended Abstracts on Human Factors in Computing Systems. ACM, 589-600. http://dx.doi.org/10.1145/2702613.2732514

44. Joanne Lo, Doris Jung Lin Lee, Nathan Wong, David Bui and Eric Paulos. 2016. Skintillates: Designing and Creating Epidermal Interactions. In Proceedings of the 2016 ACM Conference on Designing Interactive Systems (DIS'16). ACM, 853-864. http://dx.doi.org/10.1145/2901790.2901885

45. Lian Loke, Astrid Larssen, Toni Robertson and Jenny Edwards. 2007. Understanding Movement for Interaction Design: Frameworks and Approaches. Personal and Ubiquitous Computing 11,8 Special Issue Movement-Based Interaction: 691-701.

46. Lian Loke and Toni Robertson. 2013. Moving and Making Strange: An Embodied Approach to Movement-Based Interaction Design. ACM Transactions on Computer-Human Interaction (TOCHI) 20, 1: 7.

47. Lumo. 2016. Lumo Lift. Retrieved September 1, 2016 from http://www.lumobodytech.com/lumo-lift/.

48. Deborah Lupton. 2016. The Quantified Self: A Sociology of Self-Tracking Cultures. Polity Press.

49. Alasdair MacIntyre. 2013. After Virtue. A\&C Black.

50. Elena Márquez Segura, Laia Turmo Vidal, Asreen Rostami and Annika Waern. 2016. Embodied Sketching. In Proceedings of the $2016 \mathrm{CHI}$ Conference on Human Factors in Computing Systems (CHI'16). ACM, 6014-6027. https://doi.org/10.1145/2858036.2858486

51. Joe Marshall, Conor Linehan and Adrian Hazzard. 2016. Designing Brutal Multiplayer Video Games. In Proceedings of the 2016 CHI Conference on Human Factors in Computing Systems (CHI'16). ACM, 26692680. https://doi.org/10.1145/2858036.2858080

52. Joe Marshall, Florian Mueller, Steve Benford and Sebastiaan Pijnappel. 2016. Expanding Exertion Gaming. International Journal of Human-Computer Studies 90: 1-13. http://dx.doi.org/http://dx.doi.org/10.1016/j.ijhcs.2016 .02 .003

53. Joe Marshall, Duncan Rowland, Stefan Rennick Egglestone, Steve Benford, Brendan Walker and Derek McAuley. 2011. Breath Control of Amusement Rides. In Proceedings of the SIGCHI conference on Human Factors in computing systems (CHI'11). ACM, 73-82. http://dx.doi.org/10.1145/1978942.1978955

54. Mike McNamee. 2008. Sports, Virtues and Vices: Morality Plays. Routledge.

55. Florian Mueller, Stefan Agamanolis and Rosalind Picard. 2003. Exertion Interfaces: Sports over a Distance for Social Bonding and Fun. In Proceedings of SIGCHI conference on Human factors in computing systems (CHI'03). ACM, 561-568.

http://dx.doi.org/http://doi.acm.org/10.1145/642611.6 42709

56. Florian Mueller, Stefan Agamanolis, Frank Vetere and Martin Gibbs. 2009. Brute Force Interactions: Leveraging Intense Physical Actions in Gaming. In OzCHI '09: Proceedings of the 21st Annual Conference of the Australian Computer-Human Interaction Special Interest Group. ACM, 57-64. http://dx.doi.org/10.1145/1738826.1738836

57. Florian Mueller, Darren Edge, Frank Vetere, Martin. Gibbs, Stefan Agamanolis, Bert Bongers and Jennifer. Sheridan. 2011. Designing Sports: A Framework for Exertion Games. In CHI '11: Proceedings of the SIGCHI Conference on Human Factors in Computing Systems (CHI'11). ACM, 2651-2660. https://doi.org/10.1145/1978942.1979330

58. Florian Mueller, Frank Vetere, Martin Gibbs, Darren Edge, Stefan Agamanolis, Jennifer Sheridan and Jeff Heer. 2012. Balancing Exertion Experiences. In Proceedings of SIGCHI Conference on Human Factors in Computing Systems (CHI'12). ACM, 18531862. https://doi.org/10.1145/2207676.2208322

59. Florian Mueller, Frank Vetere, Martin.Gibbs, Stefan Agamanolis and Jennifer Sheridan. 2010. Jogging over a Distance: The Influence of Design in Parallel Exertion Games. In Sandbox '10: Proceedings of the 5th ACM SIGGRAPH Symposium on Video Games. ACM, 63-68. https://doi.org/10.1145/1836135.1836145

60. Florian Mueller, Frank Vetere, Martin Gibbs, Darren Edge, Stefan Agamanolis and Jennifer Sheridan. 2010. Jogging over a Distance between Europe and Australia. In UIST '10. Proceedings of the 23nd annual ACM symposium on User interface software and technology (UIST'10). ACM, 189-198. http://dx.doi.org/10.1145/1866029.1866062

61. Florian Mueller, Martin Gibbs, Frank Vetere, Stefan Agamanolis and Darren Edge. 2014. Designing 
Mediated Combat Play. In Proceedings of the 8th International Conference on Tangible, Embedded and Embodied Interaction (TEI'14). ACM, 149-156. https://doi.org/10.1145/2540930.2540937

62. Florian Mueller and Katherine Isbister. 2014. Movement-Based Game Guidelines. In Proceedings of Proceedings of the SIGCHI Conference on Human Factors in Computing Systems. ACM, 2557163, 21912200. http://dx.doi.org/10.1145/2556288.2557163

63. Florian Mueller, Cagdas Toprak, Eberhard Graether, Wouter Walmink, Bert Bongers and Elise van den Hoven. 2012. Hanging Off a Bar. In Proceedings of CHI '12 extended abstracts on Human factors in computing systems. ACM, 1055-1058. http://dx.doi.org/10.1145/2212776.2212384

64. Florian Mueller, Gunnar Stevens, Alex Thorogood, Shannon O'Brien and Volker Wulf. 2007. Sports over a Distance. Personal and Ubiquitous Computing 11, 8: 633-645. doi:10.1007/s00779-006-0133-0

65. Florian Mueller and Matthew Muirhead. 2015. Jogging with a Quadcopter. In Proceedings of the 33 rd Annual ACM Conference on Human Factors in Computing Systems (CHI'15). ACM, 2023-2032. http://dx.doi.org/10.1145/2702123.2702472

66. Florian Mueller, Martin Gibbs and Frank Vetere. 2009. The Mousegrip. In Proceedings of the 27th international conference on Human factors in Computing Systems, Extended Abstract. ACM, 31993204.

http://dx.doi.org/http://doi.acm.org/10.1145/1520340. 1520456

67. Florian Mueller, Martin Gibbs and Vetere Frank. 2010. Towards Understanding How to Design for Social Play in Exertion Games. Personal and Ubiquitous Computing 14, 5: 417-424. doi:10.1007/s00779-009-0268-x

68. Florian Mueller, Martin Gibbs and Frank Vetere. 2009. Design Influence on Social Play in Distributed Exertion Games. In Proceedings of the SIGCHI Conference on Human Factors in Computing Systems (CHI'09). ACM Press, 1539-1548.

https://doi.org/10.1145/1518701.1518938

69. Florian Mueller, Luke Cole, Shannon O'Brien and Wouter Walmink. 2006. Airhockey over a Distance: A Networked Physical Game to Support Social Interactions. In Proceedings of the 2006 ACM SIGCHI international conference on Advances in computer entertainment technology. ACM, 70. http://dx.doi.org/http://doi.acm.org/10.1145/1178823. 1178906

70. Robb Mitchell, Andreas Fender and Florian Mueller. 2016. Handyfeet: Social Bodily Play Via Split Control of a Human Puppet's Limbs. In Proceedings of the
Tenth International Conference on Tangible, Embedded, and Embodied Interaction (TEI'16). ACM, 506-511. http://dx.doi.org/10.1145/2839462.2856531

71. Nike. 2012. Nike+. Retrieved September 1, 2013 from http://nikeplus.nike.com

72. Stina Nylander, Jakob Tholander, Florian Mueller and Joe Marshall. 2015. Hci and Sports. interactions 22, 2: 30-31. http://dx.doi.org/10.1145/2559206.2559223

73 Sebastiaan Pijnappel and Florian Mueller. 2013. 4 Design Themes for Skateboarding. In Proceedings of the SIGCHI conference on Human Factors in computing systems (CHI'13). ACM, 1271-1274. https://doi.org/10.1145/2470654.2466165

74. Sebastiaan Pijnappel and Florian Mueller. 2014. Designing Interactive Technology for Skateboarding. In Proceedings of the 8th International Conference on Tangible, Embedded and Embodied Interaction (TEI'14). ACM, 141-148. http://dx.doi.org/10.1145/2540930.2540950

75. Stephen Purpura, Victoria Schwanda, Kaiton Williams, William Stubler and Phoebe Sengers. 2011. Fit4life: The Design of a Persuasive Technology Promoting Healthy Behavior and Ideal Weight. In Proceedings of the SIGCHI Conference on Human Factors in Computing Systems (CHI'11). ACM, 423432. http://dx.doi.org/10.1145/1978942.1979003

76. Yvonne Rogers. 2014. Mindless or Mindful Technology? In Proceedings of the 2014 ACM SIGCHI symposium on Engineering interactive computing systems. ACM, 241-241. http://dx.doi.org/10.1145/2607023.2611428

77. Alyson Ross and Sue Thomas. 2010. The Health Benefits of Yoga and Exercise: A Review of Comparison Studies. The journal of Alternative and complementary medicine 16, 1: 3-12.

78. m.c. schraefel. 2015. From Field to Office: Translating Brain-Body Benefits from Sport to Knowledge Work. interactions 22, 2: 32-35. http://dx.doi.org/10.1145/2732479

79. Elena Marquez Segura, Annika Waern, Jin Moen and Carolina Johansson. 2013. The Design Space of Body Games: Technological, Physical, and Social Design. In Proceedings of the SIGCHI conference on Human Factors in computing systems (CHI'13). ACM, 33653374. http://dx.doi.org/10.1145/2470654.2466461

80. Jennifer Sheridan and Florian Mueller. 2010. Fostering Kinesthetic Literacy through Exertion Games. In Workshop on Whole-Body Interactions at CHI'10: International Conference on Human Factors in Computing Systems.

81. Frank Smith. 2016. Could Hololens' Augmented Reality Change How We Study the Human Body? 
Retrieved September 1, 2016 from

http://www.edtechmagazine.com/higher/article/2016/0 4/university-testing-limits-hololens-augmented-reality.

82. Tadeusz Stach, Nicholas Graham, Jeffrey Yim and Ryan Rhodes. 2009. Heart Rate Control of Exercise Video Games. In Proceedings of Graphics Interface 2009. Canadian Information Processing Society, 125132.

83. Chek Tien Tan, Richard Byrne, Simon Lui, Weilong Liu and Florian Mueller. 2015. Joggar: A MixedModality Ar Approach for Technology-Augmented Jogging. In Proceedings of SIGGRAPH Asia 2015 Mobile Graphics and Interactive Applications. ACM, 1. http://dx.doi.org/10.1145/2818427.2818434

84. Jakob Tholander and Stina Nylander. 2015. Snot, Sweat, Pain, Mud, and Snow: Performance and Experience in the Use of Sports Watches. In Proceedings of the 33rd Annual ACM Conference on Human Factors in Computing Systems (CHI'15). ACM, 2913-2922. https://doi.org/10.1145/2702123.2702482

85. Tammy Toscos, Anne Faber, Shunying An and Mona Praful Gandhi. 2006. Chick Clique: Persuasive Technology to Motivate Teenage Girls to Exercise. In Proceedings of CHI '06 Extended Abstracts on Human Factors in Computing Systems. ACM, 1873-1878. http://dx.doi.org/10.1145/1125451.1125805.

86. Jelle van Dijk, Remko van der Lugt and Caroline Hummels. 2014. Beyond Distributed Representation: Embodied Cognition Design Supporting Socio-
Sensorimotor Couplings. In Proceedings of the 8th International Conference on Tangible, Embedded and Embodied Interaction (TEI'14). ACM, 181-188. https://doi.org/10.1145/2540930.2540934

87. Wouter Walmink, Danielle Wilde and Florian Mueller. 2014. Displaying Heart Rate Data on a Bicycle Helmet to Support Social Exertion Experiences. In Proceedings of the 8th International Conference on Tangible, Embedded and Embodied Interaction (TEI'14). ACM, 97-104. http://dx.doi.org/10.1145/2540930.2540970

88. Jin Wang, Mary She, Saeid Nahavandi and Abbas Kouzani. 2010. A Review of Vision-Based Gait Recognition Methods for Human Identification. In Proceedings of the International Conference on Digital Image Computing: Techniques and Applications (DICTA), IEEE, 320-327. https://doi.org/10.1109/DICTA.2010.62

89. Mark Weiser. 1993. Some Computer Science Issues in Ubiquitous Computing. Communications of the ACM 36, $7:$ : 75-84.

90. Jeffrey Yim and T. C. Nicholas Graham. 2007. Using Games to Increase Exercise Motivation. In Proceedings of the 2007 conference on Future Play. ACM, 166-173. http://dx.doi.org/10.1145/1328202.1328232

91. Damon. Young. 2014. How to Think About Exercise: The School of Life. Pan Macmillan UK. 